Discussion Paper No. 728

\title{
A NUMERICAL STUDY ON ASSESSING SUSTAINABLE DEVELOPMENT WITH FUTURE GENUINE SAVING SIMULATION
}

\author{
Masayuki Sato \\ Sovannroeun Samreth \\ Katsunori Yamada
}

December 2008

Revised July 2009

Secondaly Revised April 2011

The Institute of Social and Economic Research

Osaka University

6-1 Mihogaoka, Ibaraki, Osaka 567-0047, Japan 


\title{
A Numerical Study on Assessing Sustainable Development with Future Genuine Savings Simulation
}

\author{
Masayuki Sato \\ Field Science Education and Research Center, Kyoto University, Japan \\ Sovannroeun Samreth \\ Faculty of Liberal Arts, Saitama University, Japan \\ Katsunori Yamada \\ Institute of Social and Economic Research, Osaka University, Japan
}

\begin{abstract}
This paper presents a numerical examination of sustainability from the perspective of “Genuine Savings,” using a data set provided by the World Bank. Unlike previously-used criteria of sustainability that focuses on observed paths of genuine savings rates, we consider future sustainability by simulating future paths of genuine savings. This analysis shows that some countries that had been classified as being sustainable by previous studies, using observed paths, are, in fact, not sustainable from the perspective of future sustainability. We provide information on capital components which should be targeted by policymakers in order to maintain future sustainability.
\end{abstract}

Keywords: Sustainability; Development; Genuine Savings; Simulation

Acknowledgments: We would like to express our appreciation for the helpful comments offered by Akihisa Shibata, Kazuhiro Ueta and Nao Sudo. M.S. acknowledges financial support from the Integrated Research System for Sustainability Science (IR3S), particularly the Kyoto Sustainability Initiative (KSI) and from MEXT for a Grant-in Aid for Scientific Research (No. 19710041). S.S. and K.Y. acknowledge a research grant from Osaka University’s GCOE programme 'Human Behavior and Socioeconomic Dynamics'. Needless to say, we are responsible for all remaining errors in this paper. 


\section{INTRODUCTION}

The concept of genuine savings (GS), first introduced by Pearce and Atkinson (1993), is now recognized as one of the most thoroughly-researched indicators for valuating sustainable development. ${ }^{1}$ The World Bank has created a GS database and, in recent years, theoretical models for sustainability analyses using GS have been developed by studies such as Arrow, Dasgupta, and Mäler (2003a) and Dasgupta (2004). The developments in data availability and theoretical bases have prompted practical analyses of sustainability issues. Previous studies in the literature have provided useful benchmark policy implications for economic development and environment and resource exhaustion.

Hamilton and Clemens (1999) lead the empirical studies by calculating the ratio of GS to output (henceforth, GS rate) across countries for the 1970s and 1980s, as well as some single-year values for the 1990s. They then find that a wide range of countries have negative GS rates, especially in the Sub-Saharan Africa and Middle East and North Africa regions. Although rapid resource extraction is a main factor causing negative GS in these regions, they suggest that, in order to increase GS values, it is preferred to correct resource prices than to stop extracting resources altogether. In a related study, Neumayer (2000) re-investigates the GS value of the World Bank by different resource rent estimation methods, and shows that some countries that had been judged to be unsustainable in Hamilton and Clemens (1999) were in fact sustainable. Arrow et al. (2004) also calculate historical GS rates in various countries and use the averages of the observed GS rates over the three decades for their valuations of sustainability.

An issue regarding these previous studies of sustainability assessments is that the criteria that they use for assessing sustainability do not guarantee that currently-sustainable countries satisfy the sustainability criterion in the future. This point is of key importance, as one of the most influential definitions of sustainability (e.g. Arrow, Dasgupta, and Mäler, 2003a) 
requires sustainable economies to ensure non-declining welfare in the future. More importantly, Arrow, Dasgupta, and Mäler (2003a,b) also show that non-declining welfare in the future requires non-negative GS rates for any point in time onwards. In addition to this criterion, earlier theoretical studies by Asheim (1994) and Velligna and Withagen (1996) show that non-negative historical paths of GS rates are not sufficient for sustainability. ${ }^{2}$ These studies suggest that research on sustainability issues should consider not only historical paths of GS rates, but also predicted future paths of GS rates.

In this paper, unlike previously-used criteria of sustainability focused on observed paths of GS rates, we consider future sustainability using GS rates. We examine the stochastic processes of GS rate measurements from the World Development Indicators (WDI) database provided by the Word Bank. From the estimated stochastic process, we simulate the GS rate paths by countries in a Monte-Carlo fashion, and assess future sustainability of those countries. In doing so, we calculate two measures of future sustainability: (i) the percentage with which a country is likely to experience a negative GS rate within 50 years, and (ii) the average "sustained" years during which the GS rate remains positive. These criteria are motivated by Arrow, Dasgupta, and Mäler (2003a), who suggest that sustainable economies must provide non-declining welfare in the future. We expect that countries with relatively high volatilities in the stochastic process of the GS rates, and countries with low stationary GS rate values, will fail to satisfy our future sustainability criteria.

For countries that are judged as unsustainable in the future by our method, we provide some policy implications for which component of genuine savings the governments should intervene. These components include physical capital, human capital, and natural capital, and the key argument is that the government should control investments in these capital stock components to the extent that the volatility of investments is reduced.

The rest of the paper is organised as follows. In Section 2, we recap the concepts of 
genuine savings and sustainable development. In Section 3, we explain our method of analysis and the data used in this study. In Section 4, we provide estimations of the stochastic process of the GS rates, as well as simulation results, to assess future sustainability. A discussion and implications of our results follow, and Section 5 concludes the paper.

\section{SUSTAINABLE DEVELOPMENT AND GENUINE SAVING}

In this section, we recap the definition of sustainable development following a series of studies including Arrow, Dasgupta, and Mäler (2003a) and Dasgupta (2004). In these frameworks, sustainable development is defined as "non-declining welfare in the future". Following Hamilton and Atkinson (2006), in order to focus on aspects of capital accounting, we assume a fixed population.

Let $\mathrm{V}_{\mathrm{t}}$ be the discounted welfare,

$$
V_{t}=\int_{t}^{\infty} U\left(c_{t}\right) e^{-\delta(\tau-t)} d \tau,
$$

where $\mathrm{U}, \mathrm{C}$ and $\delta$ are instantaneous welfare, consumption, and discount rate, respectively. The production function is assumed to be $F(K)$, where $K$ is capital, which includes not only manmade capital but also human and natural capital. In an autonomous system, the shadow price of $j$ th capital are given as:

$$
p_{j}(t)=\partial V / \partial K_{j} .
$$

Then,

$$
\frac{d V}{d t}=\sum_{i} p_{i} \frac{d K}{d t}
$$

The right side of equation (3) is "genuine savings". Because we define sustainable development as "non-declining welfare for all points in time", we can directly express this definition as: 


$$
\frac{d V}{d t} \geq 0 \text { for all } \mathrm{t}
$$

From equations (3) and (4), this "sustainability condition",3 is satisfied if and only if

$$
G S \equiv \frac{d V}{d t}=\sum_{j} p_{j} \dot{K}_{j} \geq 0
$$

as sustainable development requires "non-negative genuine savings for all points in time". It is common that aggregate welfare is measured with consumption streams, but here, welfare $\mathrm{V}$ can instead be measured with the so-called "capital approach" in which the researcher focuses on the amount of capital that provides welfare instead of considering the levels of consumption, which is, in theory, the source of welfare.

The aggregated capital that provides welfare is called "inclusive wealth". In some literature, such as Dasgupta (2004), inclusive wealth includes not only man-made capital, human capital and natural capital, but also intangible capital such as "knowledge". Hence, inclusive wealth at time $\mathrm{t}, \mathrm{W}_{\mathrm{t}}$, can be written in monetary terms valued by shadow price, as

$$
W_{t}=K M_{t}+K H_{t}+K N_{t}+K K_{t}
$$

where $\mathrm{KM}_{\mathrm{t}}, \mathrm{KH}_{\mathrm{t}}, \mathrm{KN}_{\mathrm{t}}$ and $\mathrm{KK}_{\mathrm{t}}$ are the accumulated monetary values of man-made capital, human capital, natural capital and knowledge at time t, respectively. Even in this extended interpretation of capital, we can also conclude the same expression of inclusive wealth, genuine savings, discounted present welfare and the sustainability condition as follows.

$$
G S=\frac{d W}{d t}=\frac{d V}{d t} \geq 0, \text { for all } \mathrm{t}
$$

The intuition behind equation (7) is that if the increments of inclusive wealth at any period, namely GS, are non-negative, the welfare of next generations will not decrease. In this paper, we examine GS in evaluating the sustainability of economies with the WDI database.

In the ideal case, researchers prefer to have theory-consistent measures of inclusive wealth or GS with which to examine the sustainability condition using equation (7). However, 
the measurement of GS (also inclusive wealth) encompasses technical difficulties, and GS data provided by the WDI is not a perfect proxy for the theoretical notion of GS. The technical problems include, among others, that each GS component should be evaluated by accounting prices in the current period. However, in practice, accounting capital prices are not always available, and market prices or econometrically-computed accounting prices are used as proxies. Another issue is that the WDI database covers information on man-made capital and education expenditures as a proxy of human capital, while information on natural capital and intangible capital is quite limited. ${ }^{4}$

Despite their potential importance, construction of new proxies of natural and knowledge capital and improvements of accounting prices for GS components are beyond the scope of this study. In this paper, we confine our attention to the issue of future sustainability of economies that have been neglected in the literature. Hence, we take GS data from the WDI database as a proxy of the theoretical notion of genuine savings in Arrow, Dasgupta, and Mäler (2003a,2003b).

\section{METHODS AND DATA}

\subsection{Theoretical Backgrounds}

As documented in the previous section, we exploit equation (7) by evaluating the sustainability of economies. Note that if an economy stays on a balanced growth path, the GS level continually increases, and the GS rate remains constant along the steady growth path. In such a case, as previous studies, such as Hamilton and Clemens (1999) and Neumayer (2000), have argued, a non-negative current GS rate or positive historical average of GS rates are sufficient for confirming sustainability in the future. ${ }^{5}$ However, when an economy is not on a balanced growth path, possibly due to structural or environmental changes, growth patterns in the GS rate will be non-monotonic, and historical averages or currently positive GS rates are 
not so informative in evaluating future sustainability. As the real world phenomena and various data sets suggest, economies are usually on transitional paths after being hit by various kinds of exogenous shocks or structural changes. In these cases, we may overlook the possibility that the sustainability condition given by equation (7) may be violated in the future when we merely consider the historical average of GS rates, as has been done in previous studies. Hence, in this paper we consider "future sustainability" by predicting time series paths of GS rates, using simulation methods.

In general, transition equations for savings rates are non-linear from any kind of formal models. In this paper, instead of referring to a specific theoretical background and working on non-linear equations of GS rate evolutions, we assume that transition paths of GS rates can be approximated via the $\mathrm{AR}(1)$ process. This is a simplifying assumption, but will be a useful first-step benchmark for predicting future sustainability.

\subsection{Empirical Methods}

As stated above, we estimate the AR(1) processes of GS rates as

$$
G S_{t, i}=\text { const }_{i}+\beta G S_{t-1, i}+\varepsilon_{i}
$$

where $\varepsilon \sim\left(0, \sigma^{2}\right)$ is a normally-distributed random term and $i$ is the country index. Using estimated AR(1) processes and the initial conditions (i.e., the latest GS rates available in the dataset used), we obtain predicted GS rate paths for examining future sustainability in a Monte-Carlo fashion. In this study, we assess future sustainability for each country by considering two measures of future sustainability: (i) the percentage with which a country is likely to experience a negative GS rate within a certain number of years, and (ii) the average "sustained" years during which the GS rate remains positive. These criteria are motivated by Arrow, Dasgupta, and Mäler (2003a), who suggest that sustainable economies must provide non-declining welfare in the future. We expect that countries with relatively high volatilities 
in the stochastic process of the GS rates, and countries with low stationary GS rates, will fail to satisfy our future sustainability criteria. For the first criterion, we consider the time periods of 25 years and 50 years. ${ }^{6}$

Using the estimated trend and the constant terms in the AR(1) results, we can estimate stationary GS rates for each country. As will be shown, a larger $\sigma$ (higher GS volatility) indicates a higher the possibility of violating the condition of sustainability for a given initial condition. Further, if a country is endowed with a lower stationary GS rate, it tends to violate the condition of sustainability for a given GS volatility as well. ${ }^{7}$

Our estimation results of the AR(1) process for the GS rate time series are given in Table 1. Overall, our results suggest that the estimated AR(1) processes have trend terms less than one and positive constant terms. ${ }^{8}$ This indicates that, in those countries, the AR(1) processes are stationary and have positive steady state GS rates between zero and one. For some countries, the estimated constant term in equation (8) is not statistically significant even at the 10 percent level. However, if we omit the constant term in our simulations, it follows that the GS rates in those cases trivially approach zero with estimated trend terms of less than one. Therefore, in order to exclude these trivial results, we still employ the estimated constants, even when they are not statistically significant. Note that the bias of this procedure is that we underestimate the possibility of violating future sustainability conditions. There may even be underestimations as a result of countries that violate the future sustainability conditions. Importantly, some of these countries have non-negative current GS rates, which are required as a sustainable criterion in previous studies.

Some remarks on our empirical strategy are in order. One of the reasons that we employ the $\mathrm{AR}(1)$ process for the GS rate is that there was a lack of sufficient time series data with which to conduct more complex stochastic processing. Additionally, in order to confirm how our AR(1)-based simulation process can explain the actual GS data, we conduct the 
simulation based on the parameters (constant and trend terms in Table 1) drawn from the results of our AR(1) estimation by taking the oldest GS data available in each country as the initial value in projecting the simulated values of GS in the years ahead. The number of years during which the simulated GS value is projected differs from country to country based on available sample size in the WDI database. The projection of GS value is conducted with 10,000 iterations and a 95 percent interval is created based on these results. The figures illustrated the actual data from the WDI database, as well as the lower and upper bounds of 95 percent interval drawn from simulation results, show that nearly all of the actual values of GS lie within the simulated 95 percent interval. ${ }^{9}$ This supports our strategy of employing $\mathrm{AR}(1)$ processes. Moreover, when examining the AR(1) process, we assume away unit root - if we have a GS rate process that has a unit root, then the GS rate of the country would eventually diverge with time. Hence, we assume that the GS process does not have a unit root.

\subsection{Data}

With respect to the measurement of GS, we use the WDI (2007) database released by the World Bank. The WDI database provides data on both GS as the share of Gross Nation Income (GNI) and on its components. ${ }^{10}$ As mentioned above, GS in the WDI database is defined as the sum of physical capital investment (net national savings; $d K M_{t} / d t$ ), human capital investment (education expenditures; $d K H_{t} / d t$ ), and the damage to or degradation of natural resources (energy depletion, mineral depletion, forest depletion, $\mathrm{CO}_{2}$ emissions; $\left.d K N_{t} / d t\right) .{ }^{11}$ For statistical descriptions of the GS measurements, Hamilton and Atkinson (2006) and Gnègnè (2009) provided detailed and comprehensive illustrations.

The database contains information on 208 countries and regions. However, owing to the fact that the sample size must be sufficiently large to conduct AR(1) analysis, those countries 
with continuous sample sizes of less than 20 years were dropped from our analysis. For countries with missing values in their data, we select the time span with more than 20 continuous years of data. ${ }^{12}$ In some empirical studies, when a small number of missing values (e.g., GDP) exist in the data, simple statistical methods, such as averaging, are used to complement the missing data; however, we do not apply such methods in the present study because mere averaging is likely to result in false imputations when GS measures are highly volatile. Following this process, more than half of the countries are excluded. 85 countries, as listed in Tables 1 and A1, are chosen for our study. ${ }^{13}$

\section{RESULTS}

The results are shown in Tables 1 and A1. Table 1 recaps the findings of Hamilton and Clemens (1999) and Arrow, et al. (2004) and presents our simulation results of future sustainability. Note that although our analysis considers only those cases in which the GS data is listed as a percentage of GNI (or GNP), when the GS data is listed as a percentage of GDP, we obtain similar implications.

Our results indicate that our judgements on sustainability differ from those of Hamilton and Clemens (1999), as well as those of Arrow, et al. (2004), in many countries. ${ }^{14}$ This is because our analysis takes into account the trend and volatility of the time series path of each country's GS. Our analytical framework provides more insightful information on sustainability assessment.

The estimation results of the AR(1) processes of GS rates are also provided. Table A1 presents the residual standard deviations of $\operatorname{VAR}(1)$ for the vector of $(\mathrm{KM}, \mathrm{KH}, \mathrm{KN}) .{ }^{15} \mathrm{We}$ present the standard deviations in order to determine which component is contributing to GS rate volatility in total, since this information is useful for policymakers in identifying which component should be their policy target. 


\section{Table1}

\section{Latin America and the Caribbean}

Hamilton and Clemens (1999) suggest that Belize, Brazil, Chile, Costa Rica, Dominican Republic, El Salvador, Guatemala, Mexico and Paraguay are sustainable countries, while Bolivia, Ecuador, Jamaica, Trinidad and Tobago, and Venezuela are unsustainable. However, our simulations provide a new view. Belize, Chile, El Salvador, Guatemala and Mexico face a very high probability of violating the future condition of sustainability, even though they have current non-negative GS rates. The situation in Costa Rica and Paraguay is ambiguous, since the probabilities are relatively lower in these countries. Regarding Jamaica, while Hamilton and Clemens (1999) find a negative current GS rate, our simulation reveals that the probability of violating future sustainability is approximately 85 percent. This figure is better than that of Mexico, for example (96 percent), which Hamilton and Clemens (1999) judge to be sustainable. Paraguay is also of interest, since it has a much smaller probability of violating future sustainability (26 percent) compared to Mexico, although Hamilton and Clemens (1999) judge Paraguay's sustainability to be on the margin (1.0). Guatemala's situation is in sharp contrast to that of Paraguay_according to Hamilton and Clemens (1999), the sustainability of Guatemala was also on the margin (1.2), whereas our simulations show that its probability of violating future sustainability is as high as 97 percent. This is because Guatemala has higher volatility in the GS rate path relative to its stationary level. From Table A1, we can see that in countries in the Latin America and Caribbean region, high volatilities in GS rate paths are generally attributable to the component of physical capital. Perhaps Mexico is an exception in that energy depletion will be a source of fluctuation. 


\section{East and Southeast Asia}

Both Hamilton and Clemens (1999) and Arrow, et al. (2004) find China to be sustainable. These findings are consistent with those of our study. However, we should remain alert to China's case, as its probability of violating future sustainability is slightly positive (16 percent). Based on our results, Hong Kong, Republic of Korea, the Philippines and Thailand are robustly sustainable. These findings are consistent with those of Hamilton and Clemens (1999). In this region, Malaysia will be an exception, with a higher probability of violating future sustainability (57 percent). The findings in Table A1 suggest that this is due to high volatility in human capital investment and energy resource depletion.

\section{Middle East and North Africa}

Arrow, et al. (2004) suggest that countries in the Middle East and North Africa are generally unsustainable, as the unsustainable countries in this region excessively depend on their oil resources. Hamilton and Clemens (1999) propose a different view, indicating that Algeria, Israel, Jordan, Morocco and Tunisia are in fact sustainable. However, our analysis suggests that Algeria and Israel, in fact, have high probabilities of experiencing a negative GS rate (around 90 percent). Hence, our results are more akin to those of Arrow, et al. (2004) with regard to these two countries. In the case of Jordan, it is difficult to make a clear judgement from the viewpoint of the probability of a negative GS rate. Our results note that, on average, the period until Jordan first experiences a negative rate of GS is around 60 years. While little can be determined about welfare parity issues among generations, this long sustainable period (two generations) provides sufficient evidence to state that the country is sustainable. As for Morocco and Tunisia, we suggest that they are sustainable. This is in line with the results of Hamilton and Clemens (1999). From Table A1, energy depletion can be considered the main cause of GS rate volatility in the region. 


\section{South Asia}

Arrow, et al. (2004) indicate that all South Asian countries are sustainable. This finding is contrast with that of Hamilton and Clemens (1999) in the case of Nepal, which they find to be unsustainable. Our study suggests that Nepal will remain sustainable over the 50 -year period. Contrary to the two aforementioned studies, we suggest that Bangladesh and Pakistan might be unsustainable. ${ }^{16}$ From Table A1, we can see that in this region the main cause of high volatility in the GS rate is the volatility in physical capital investment.

\section{Sub-Saharan Africa}

Arrow, et al. (2004) suggest that Sub-Saharan Africa in general is unsustainable. Our results concur, except for the cases of Botswana, Kenya and Mauritius. Hamilton and Clemens (1999) also find Kenya and Mauritius to be sustainable. Note that Burkina Faso, South Africa and Zimbabwe are found to be unsustainable from the results of our simulation. These findings are not consistent with those of Hamilton and Clemens (1999), primarily because the paths of these countries' GS rates are highly volatile relative to the stationary level of the GS rate. From Table A1, we find that many countries in this region have relatively high volatility of natural capital.

\section{High-Income Countries}

For high-income countries, our analysis generally concurs with previous studies. However, there are some interesting cases. Contrary to previous two studies, Portugal seems to have very risky sustainability. Although the United Kingdom and United States have similar steady state GS rates, their probabilities of violating the condition of sustainability is quite different, and the United States suffers from a fairly high probability of violating the 
condition of future sustainability ( 29 percent). The reason for this is the volatility in human capital investment as shown in Table A1. Australia, Greece and Portugal all have a non-negligible probability of violating the condition of future sustainability ( 24 percent, 43 percent, and 71 percent, respectively), and in these cases, stabilisation of physical capital investment should be the policy target.

\section{CONCLUSION}

In this paper, we provide a numerical examination of future sustainability using the World Bank's WDI database. Our focus is not on the historical averages of GS rates, but on the stochastic process. This is because, depending on the volatilities, steady state GS rate values, and initial conditions, some countries may violate the condition of future sustainability even though they satisfy the criterion of sustainability proposed by previous studies. By taking into account the future paths of GS rates, interestingly, our results differ from those of previous studies, as we find that some countries, previously judged to be sustainable, are, in fact, confronting unsustainability. The results indicate that trends and volatilities of the stochastic process of GS rates are of non-negligible importance in the assessment of sustainability. We also provide information on which component contributes most to a high volatility of the GS rate. This information is important in identifying policy targets.

Some remarks on potential future work are in order. First, the GS series in the WDI database used by this study includes only specific capitals which are evaluated at specific shadow prices. Hence, it loses touch with the original concept of "change of inclusive wealth". At present, needless to say, the WDI is one of the most reliable sources on GS data, but further improvements will be required to bridge the conceptual gap.

Second, policy analyses should be conducted in more detail. In this paper, we suggested 
an assessment of future sustainability and contributed to the literature with findings that are relevant to the policy discussion. More detailed model analyses, which will complement the findings and speculations we obtained by conducting a simple numerical examination, are necessary in order to draw more detailed implications for policymakers. This includes the consideration of exogenous shocks.

\section{APPENDIX}

\section{Table A1}




\section{References}

Arrow, K., Dasgupta, P., Goulder, L., Daily, G., Ehrlich, P., Heal, G., Levin, S., Mäler, K.-G., Schneider, S., Starrett, D. and Walker, B. (2004) 'Are We Consuming Too Much?', Journal of Economic Perspectives, Vol. 18, No. 3, pp. 147-172.

Arrow, K., Dasgupta, P. and Mäler, K.-G. (2003a) 'Evaluating Projects and Assessing Sustainable Development in Imperfect Economies', Environmental and Resource Economics, Vol. 26, No. 4, pp. 647-685.

Arrow, K., Dasgupta, P. and Mäler, K.-G. (2003b) 'The Genuine Savings Criterion and the Value of Population', Economic Theory, Vol. 21, pp. 217-225.

Asheim, G. B. (1994) 'Net National Product as an Indicator of Sustainability', Scandinavian Journal of Economics, Vol. 96, No. 2, pp. 257-265.

Dasgupta, P. (2004) Human Well-Being and the Natural Environment, New York: Oxford University Press.

Dasgupta, P. (2007) Economics: A Very Short Introduction, New York: Oxford University Press.

Hamilton, K. and Atkinson, G. (2006) Wealth, Welfare and Sustainability, Cheltenham: Edward Elgar.

Hamilton, K. and Clemens, M. (1999) 'Genuine Savings Rates in Developing Countries', World Bank Economic Review, Vol. 13, No. 2, pp. 333-356.

Hamilton, K. and Hartwick, J. (2005) 'Investing Exhaustible Resource Rents and the Path of Consumption', Canadian Journal of Economics, Vol. 38, No. 2, pp. 615-621.

Neumayer, E. (2000) 'Resource Accounting in Measures of Unsustainability: Challenging the World Bank's Conclusions', Environmental and Resource Economics, Vol. 15, No. 3, pp. 257-278.

Gnègnè, Y. (2009) 'Adjusted Net Saving and Welfare Change', Ecological Economics, Vol. 
68, pp. 1127-1139.

Pearce, D. W. and Atkinson, G. D. (1993) 'Capital Theory and the Measurement of Sustainable Development: An Indicator of "Weak” Sustainability”, Ecological Economics, Vol. 8, No. 2, pp. 103-108.

Stiglitz J. E., Sen, A. and Fitoussi, J-P. (2009) 'Report by the commission on the measurement of economic performance and social progress'.

(Available at http://www.stiglitz-sen-fitoussi.fr/documents/rapport_anglais.pdf)

Yamaguchi, R., Sato, M. and Ueta, K. (2009) 'Genuine Saving with Adjustment Costs', Paper Presented at the $17^{\text {th }}$ Annual Conference of EARE, VU University, Netherlands.

Valente, S. (2008) 'Optimal Growth, Genuine Savings and Long-Run Dynamics', Scottish Journal of Political Economy, Vol. 55, No. 2, pp. 210-226.

Vellinga, N. and Withagen, C. (1996) 'On the Concept of Green National Income', Oxford Economic Papers, Vol. 48, No. 4, pp. 499-514. 


\section{NOTES}

${ }^{1}$ Genuine savings is also referred to as 'Genuine Investment' (Arrow, Dasgupta, and Mäler, 2003), 'Adjusted Net Saving' (World Bank) and 'Inclusive Investment' (Dasgupta, 2007). All of these terms imply a change of wealth as a source of welfare.

${ }^{2}$ Also, Valente (2008) analytically investigates a one-to-one relationship between the sign of the average long-run GS rates and the limiting condition for sustained utility in the framework of a capital resource growth model. Hamilton and Hartwick (2005) investigate the timing of zero net investment in an unsustainable economy in which the future GS rate is negative.

${ }^{3}$ In assessing sustainability, "genuine savings" is a weak sustainability indicator.

${ }^{4}$ Available information from the WDI for natural capital includes natural capital depletions such as energy depletion $\left(E N E R_{t}\right)$, mineral depletion $\left(M I N E_{t}\right)$, forest depletion $\left(F O R E_{t}\right)$ and carbon dioxide damages $\left(\mathrm{CO} 2_{t}\right)$.

${ }^{5}$ Following the literature, we consider the evolution of GS rates rather than that of GS levels themselves. This is because, by doing so, we can control for scale effects of the economy. Also, note that negative GS rates mean negative GS levels.

6 The python code for our simulation is available upon request from the authors. In our study, the figures are obtained by 10,000 iterations of the simulation. The 25 -year simulation is conducted to check for robustness in our simulation.

7 The high volatility of GS has other problems as well, including adjustment costs (see Yamaguchi, Sato, and Ueta, 2009) and intergenerational inequality.

${ }^{8}$ The regression results show that the trend coefficient of Chad is greater than one, indicating that the GS value will diverge, and Chad is thus excluded from the simulation analysis.

9 The graphs are available upon request.

${ }^{10}$ In previous studies, various calculations were adopted (e.g. per GNI, per GDP). In this paper, we use GS as the share of GNI. When we compare with other studies, we will note the difference of expression of GS.

$11 \mathrm{GS}$, here, is referred to as adjusted net savings in the WDI database.

12 For example, Cameroon's data cover the period of 1970 to 2005. However, since there is missing values for 1999, the sample chosen for conducting AR(1) for the case of Cameroon is from 1970 to 1998 (29 years).

${ }^{13}$ As stated in footnote 8, although the sample size of Chad is sufficient, it is excluded from the analysis.

${ }^{14}$ While we use only the results of the 50-year simulation for discussion, similar implications are obtained when the 25 -year simulation is conducted.

15 We find that covariance components in the variance-covariance matrix play rather minor roles. Hence, in this paper we present only the variance components.

${ }^{16}$ Hamilton and Clemens (1999) note that Bangladesh has frequent negative GS events before 1993. 
Table 1: Comparison of GS as percentage of output and simulation results

\begin{tabular}{|c|c|c|c|c|c|c|c|c|c|c|}
\hline \multirow[b]{3}{*}{ Country } & \multicolumn{2}{|c|}{$\begin{array}{|cc|}(1) & (2) \\
\text { Hamilton and } & \text { Arrow et al . } \\
\text { Clemens } & (2004) \\
(1999) & \\
\end{array}$} & & & & & $\begin{array}{c}\text { (3) } \\
\text { This study }\end{array}$ & & & \\
\hline & \multirow[b]{2}{*}{$\begin{array}{l}\text { GS as } \\
\text { percent of } \\
\text { GNP }\end{array}$} & \multirow[b]{2}{*}{$\begin{array}{l}\text { GS as } \\
\text { percent of } \\
\text { GDP }\end{array}$} & \multicolumn{4}{|c|}{ Estimated results of $A R(1)$ process } & \multicolumn{4}{|c|}{ Simulation results } \\
\hline & & & constant & $\beta$ & $\begin{array}{l}\text { St. dev. } \\
\text { of } \varepsilon\end{array}$ & $\begin{array}{c}\text { Steady } \\
\text { state GS } \\
\text { rate }\end{array}$ & $\begin{array}{c}\text { Initial } \\
\text { condition }\end{array}$ & $\begin{array}{c}\% \text { of } \\
\text { experiencing } \\
\text { negative GS in } \\
25 \text { years }\end{array}$ & $\begin{array}{c}\% \text { of } \\
\text { experiencing } \\
\text { negative GS in } \\
50 \text { years }\end{array}$ & $\begin{array}{c}\text { Average years } \\
\text { before having } \\
\text { negative GS }\end{array}$ \\
\hline \multicolumn{11}{|c|}{ Latin America and the Caribbean } \\
\hline Belize & 16.7 & & $1.10(2.03)$ & $0.87(0.12)$ & 5.61 & 8.61 & 0.4 & 89.20 & 93.00 & 16.09 \\
\hline Bolivia & -15.4 & & $-1.11(0.85)$ & $0.83(0.10)$ & 4.96 & -6.66 & -18.72 & 100.00 & 100.00 & N.A. ${ }^{a}$ \\
\hline Brazil & 11.8 & & $2.81(1.30)$ & $0.72(0.12)$ & 2.04 & 9.97 & 8.31 & 0.80 & 1.34 & $>1000$ \\
\hline Chile & 13.2 & & $-0.16(0.72)$ & $0.92(0.08)$ & 3.57 & -2.13 & -4.93 & 99.70 & 99.94 & N.A. ${ }^{a}$ \\
\hline Costa Rica & $14.7\left(^{*}\right)$ & & $1.43(0.74)$ & $0.87(0.08)$ & 2.52 & 11.43 & 16.62 & 8.10 & 22.80 & 182.07 \\
\hline Dominica & & & $0.08(1.70)$ & $0.84(0.15)$ & 5.55 & 0.50 & -6.42 & 99.30 & 100.00 & N.A. ${ }^{a}$ \\
\hline Dominican Republic & 10.3 & & $12.87(2.35)$ & $-0.00(0.18)$ & 3.33 & 12.81 & 7.75 & 0.20 & 0.29 & N.A. ${ }^{b}$ \\
\hline Ecuador & -4.1 & & $-1.29(0.80)$ & $0.88(0.08)$ & 3.62 & -10.68 & -14.06 & 100.00 & 100.00 & N.A. ${ }^{a}$ \\
\hline El Salvador & 5.9 & & $1.26(0.97)$ & $0.80(0.11)$ & 3.24 & 6.26 & 2.04 & 77.60 & 92.20 & 16.01 \\
\hline Fiji & & & $3.27(1.66)$ & $0.70(0.13)$ & 4.12 & 10.78 & 38.80 & 27.90 & 53.81 & 63.87 \\
\hline Guatemala & 1.2 & & $0.31(0.36)$ & $0.85(0.09)$ & 1.66 & 2.11 & 2.87 & 81.50 & 97.40 & 14.23 \\
\hline Honduras & & & $1.68(1.29)$ & $0.91(0.08)$ & 3.84 & 17.76 & 23.29 & 10.30 & 24.60 & 180.49 \\
\hline Jamaica & -2.4 & & $1.50(1.18)$ & $0.85(0.09)$ & 4.88 & 10.04 & 14.55 & 62.20 & 84.29 & 28.91 \\
\hline Mexico & 3.6 & & $0.38(0.59)$ & $0.88(0.07)$ & 2.64 & 3.22 & 4.01 & 82.70 & 95.52 & 14.98 \\
\hline Nicaragua & & & $-2.23(2.44)$ & $0.69(0.13)$ & 13.30 & -7.10 & 5.51 & 100.00 & 100.00 & N.A. ${ }^{a}$ \\
\hline Paraguay & 1.0 & & $5.51(1.72)$ & $0.48(0.15)$ & 3.77 & 10.56 & 10.4 & 13.60 & 25.82 & 159.58 \\
\hline \multicolumn{3}{|c|}{ St. Vincent and the Grenadines } & $6.52(2.71)$ & $0.50(0.17)$ & 7.30 & 13.14 & 5.66 & 70.50 & 90.48 & 20.48 \\
\hline Tonga & & & $10.68(3.65)$ & $0.35(0.21)$ & 7.38 & 16.34 & 22.58 & 34.50 & 56.70 & 55.88 \\
\hline Trinidad and Tobagd & -7.9 & & $-3.34(1.66)$ & $0.64(0.14)$ & 7.73 & -9.21 & -22.90 & 100.00 & 100.00 & N.A. ${ }^{a}$ \\
\hline Uruguay & & & $2.73(1.38)$ & $0.64(0.14)$ & 4.87 & 7.55 & 3.13 & 84.60 & 97.07 & 12.52 \\
\hline Venezuela, RB & -14.5 & & $-1.07(1.09)$ & $0.80(0.09)$ & 6.33 & -5.31 & -6.91 & 100.00 & 100.00 & N.A. ${ }^{a}$ \\
\hline \multicolumn{11}{|c|}{ East Asia and the Pacific } \\
\hline China & 21.5 & 22.72 & $0.86(1.19)$ & $0.97(0.06)$ & 4.18 & 26.38 & 33.20 & 5.30 & 16.29 & 218.81 \\
\hline Hong Kong, China & $\left.21.7{ }^{* \star}\right)$ & & $14.38(3.51)$ & $0.33(0.16)$ & 2.00 & 21.42 & 21.56 & 0.00 & 0.00 & N.A. ${ }^{b}$ \\
\hline Korea, Rep. & 29.6 & & $3.27(1.64)$ & $0.86(0.07)$ & 2.49 & 23.72 & 22.12 & 0.00 & 0.00 & N.A. ${ }^{b}$ \\
\hline Malaysia & 18.6 & & $1.22(1.21)$ & $0.90(0.08)$ & 3.46 & 11.86 & 9.18 & 38.00 & 56.80 & 62.85 \\
\hline Philippines & 8.0 & & $2.89(1.53)$ & $0.83(0.10)$ & 3.33 & 16.80 & 21.29 & 2.10 & 5.28 & 747.32 \\
\hline Thailand & 28.1 & & $2.98(1.75)$ & $0.85(0.09)$ & 2.20 & 20.07 & 18.56 & 0.00 & 0.00 & N.A. ${ }^{b}$ \\
\hline \multicolumn{2}{|c|}{ Middle East/ North Africa } & -7.09 & & & & & & & & \\
\hline Algeria & 6.7 & & $1.88(1.29)$ & $0.73(0.12)$ & 3.94 & 7.06 & -1.73 & 88.80 & 96.29 & 0.00 \\
\hline Israel & 16.7 & & $3.64(1.34)$ & $0.45(0.18)$ & 3.81 & 6.65 & 9.39 & 68.00 & 90.38 & 22.65 \\
\hline Jordan & 13.5 & & $9.53(4.35)$ & $0.36(0.26)$ & 6.46 & 14.89 & 0.13 & 34.80 & 55.20 & 65.26 \\
\hline Morocco & 15.2 & & $1.55(1.33)$ & $0.92(0.09)$ & 2.54 & 18.63 & 23.95 & 0.30 & 2.09 & $>1000$ \\
\hline Saudi Arabia & -20.2 & & $-7.03(3.51)$ & $0.65(0.14)$ & 4.60 & -20.22 & -13.72 & 100.00 & 100.00 & N.A. ${ }^{a}$ \\
\hline Syrian Arab Republi & $\left.-10{ }^{* *}\right)$ & & $-2.02(1.38)$ & $0.91(0.09)$ & 6.95 & -23.60 & -38.47 & 100.00 & 100.00 & N.A. ${ }^{a}$ \\
\hline Tunisia & 12.8 & & $2.03(1.24)$ & $0.84(0.10)$ & 1.69 & 13.04 & 8.98 & 0.40 & 0.10 & N.A. ${ }^{b}$ \\
\hline
\end{tabular}


Table 1: Comparison of GS as percentage of output and simulation results (contd)

\begin{tabular}{|c|c|c|c|c|c|c|c|c|c|c|}
\hline \multirow[b]{3}{*}{ Country } & \multirow{3}{*}{$\begin{array}{c}1) \\
\begin{array}{c}\text { Hamilton and } \\
\text { Clemens } \\
(1999)\end{array} \\
\text { GS as } \\
\text { percent of } \\
\text { GNP }\end{array}$} & \multirow{3}{*}{$\begin{array}{c}\text { (2) } \\
\begin{array}{c}\text { Arrow et al . } \\
(2004)\end{array} \\
\text { GS as } \\
\text { percent of } \\
\text { GDP }\end{array}$} & \multicolumn{8}{|c|}{$\begin{array}{c}\text { (3) } \\
\text { This study }\end{array}$} \\
\hline & & & \multicolumn{4}{|c|}{ Estimated results of $A R(1)$ process } & \multicolumn{4}{|c|}{ Simulation results } \\
\hline & & & constant & $\beta$ & $\begin{array}{l}\text { St. dev. } \\
\text { of } \varepsilon\end{array}$ & $\begin{array}{c}\text { Steady } \\
\text { state GS } \\
\text { rate }\end{array}$ & $\begin{array}{c}\text { Initial } \\
\text { condition }\end{array}$ & $\begin{array}{c}\% \text { of } \\
\text { experiencing } \\
\text { negative GS in } \\
25 \text { years }\end{array}$ & $\begin{array}{c}\% \text { of } \\
\text { experiencing } \\
\text { negative GS in } \\
50 \text { years }\end{array}$ & $\begin{array}{c}\text { Average years } \\
\text { before having } \\
\text { negative GS }\end{array}$ \\
\hline \multicolumn{11}{|l|}{ South Asia } \\
\hline Bangladesh & 2.4 & 7.14 & $1.25(0.80)$ & $0.91(0.08)$ & 3.66 & 13.56 & 17.51 & 22.40 & 43.49 & 83.72 \\
\hline India & 7.2 & 9.47 & $0.82(0.93)$ & $0.95(0.09)$ & 1.90 & 17.23 & 19.35 & 0.20 & 1.72 & $>1000$ \\
\hline Nepal & -12.3 & 13.31 & $1.43(0.96)$ & $0.94(0.07)$ & 2.79 & 24.14 & 23.03 & 1.30 & 1.81 & $>1000$ \\
\hline Pakistan & 4.7 & 8.75 & $2.12(1.06)$ & $0.76(0.11)$ & 2.90 & 8.88 & 2.39 & 41.10 & 55.77 & 71.43 \\
\hline Sri Lanka & 12.4 & & $5.97(2.10)$ & $0.59(0.14)$ & 3.04 & 14.70 & 12.47 & 0.20 & 0.21 & N.A. ${ }^{b}$ \\
\hline Sub-Saharan Africa & & -2.09 & & & & & & & & \\
\hline Benin & 0.8 & & $0.38(0.66)$ & $0.38(0.16)$ & 3.83 & 0.61 & 3.04 & 100.00 & 100.00 & N.A. \\
\hline Botswana & & & $4.46(2.51)$ & $0.87(0.08)$ & 5.91 & 33.16 & 39.06 & 2.20 & 4.87 & 835.58 \\
\hline Burkina Faso & 8.6 & & $1.78(1.02)$ & $0.72(0.14)$ & 2.83 & 6.51 & 1.54 & 61.80 & 83.10 & 26.39 \\
\hline Cameroon & -0.6 & & $-0.46(1.02)$ & $0.36(0.16)$ & 5.80 & -0.73 & -2.57 & 100.00 & 100.00 & N.A. ${ }^{a}$ \\
\hline Congo, Dem. Rep. & & & $-3.31(1.38)$ & $0.28(0.17)$ & 6.45 & -4.62 & 1.86 & 100.00 & 100.00 & N.A. ${ }^{a}$ \\
\hline Congo, Rep. & -28.6 & & $-16.84(6.15)$ & $0.35(0.23)$ & 12.67 & -26.09 & -46.52 & 100.00 & 100.00 & N.A. ${ }^{a}$ \\
\hline Cote d'Ivoire & -12.3 & & $1.66(1.35)$ & $0.67(0.17)$ & 5.12 & 4.99 & 2.37 & 97.30 & 99.40 & 8.37 \\
\hline Ethiopia & & & $2.00(1.19)$ & $0.80(0.12)$ & 4.02 & 9.87 & 12.65 & 46.70 & 73.22 & 38.74 \\
\hline Ghana & -4.6 & & $0.54(0.87)$ & $0.83(0.10)$ & 4.95 & 3.25 & 13.45 & 87.90 & 99.70 & 7.621 \\
\hline Kenya & 1.4 & & $9.74(2.21)$ & $0.21(0.17)$ & 3.11 & 12.35 & 8.46 & 0.30 & 0.36 & N.A. ${ }^{b}$ \\
\hline Lesotho & & & $4.02(1.97)$ & $0.80(0.09)$ & 7.35 & 20.46 & 19.35 & 42.20 & 65.80 & 50.52 \\
\hline Madagascar & -0.2 & & $0.40(0.74)$ & $0.49(0.15)$ & 4.30 & 0.78 & 5.86 & 100.00 & 100.00 & N.A. \\
\hline Mauritania & -14.9 & & $-12.39(4.08)$ & $0.32(0.17)$ & 16.96 & -18.26 & -40.21 & 100.00 & 100.00 & N.A. ${ }^{a}$ \\
\hline Mauritius & 18.3 & & $2.34(1.63)$ & $0.87(0.09)$ & 1.93 & 17.54 & 11.57 & 0.00 & 98.80 & 6.61 \\
\hline Rwanda & -1.4 & & $2.63(1.10)$ & $0.57(0.15)$ & 4.41 & 6.09 & 12.45 & 87.20 & 98.19 & 13.67 \\
\hline Senegal & 3.2 & & $0.14(0.73)$ & $0.90(0.08)$ & 4.29 & 1.32 & 9.75 & 87.50 & 99.20 & 6.688 \\
\hline Sierra Leone & $-2.7\left(^{* *}\right)$ & & $-5.42(1.99)$ & $0.19(0.20)$ & 6.73 & -6.66 & -2.06 & 100.00 & 100.00 & N.A. ${ }^{a}$ \\
\hline South Africa & 5.2 & & $2.94(1.26)$ & $0.30(0.26)$ & 2.07 & 4.18 & 0.40 & 47.00 & 71.90 & 39.73 \\
\hline Swaziland & & & $2.81(1.64)$ & $0.75(0.12)$ & 4.90 & 11.17 & 12.01 & 55.30 & 77.76 & 32.65 \\
\hline Togo & -12.5 & & $0.76(1.13)$ & $0.55(0.18)$ & 5.07 & 1.68 & 0.66 & 100.00 & 100.00 & N.A. ${ }^{a}$ \\
\hline Uganda & -8.6 & & $-1.34(0.73)$ & $0.68(0.11)$ & 3.73 & -4.15 & 1.14 & 100.00 & 100.00 & N.A. ${ }^{a}$ \\
\hline Zambia & -16.1 & & $-2.77(2.32)$ & $0.73(0.14)$ & 7.40 & -10.32 & -3.97 & 100.00 & 100.00 & N.A. ${ }^{a}$ \\
\hline Zimbabwe & 8.7 & & $1.69(2.76)$ & $0.70(0.26)$ & 5.39 & 5.60 & -8.46 & 98.70 & 100.00 & N.A. ${ }^{a}$ \\
\hline \multicolumn{11}{|c|}{ High-Income Countries } \\
\hline Australia & 5.5 & & $1.43(0.78)$ & $0.77(0.09)$ & 1.69 & 6.35 & 3.99 & 15.20 & 23.76 & 193.83 \\
\hline Austria & 16.2 & & $3.65(1.51)$ & $0.73(0.11)$ & 1.34 & 13.53 & 15.52 & 0.00 & 0.00 & N.A. ${ }^{b}$ \\
\hline Belgium & 16.7 & & $2.89(1.42)$ & $0.77(0.09)$ & 2.70 & 12.70 & 10.84 & 4.10 & 4.97 & $>1000$ \\
\hline Canada & 7.4 & & $1.50(1.06)$ & $0.82(0.10)$ & 1.63 & 8.46 & 4.76 & 2.90 & 5.62 & $>1000$ \\
\hline Denmark & 14.2 & & $1.20(0.89)$ & $0.89(0.07)$ & 1.39 & 11.15 & 14.31 & 0.20 & 0.34 & N.A. ${ }^{b}$ \\
\hline Finland & 5.5 & & $2.23(1.28)$ & $0.82(0.09)$ & 2.44 & 12.12 & 12.30 & 2.40 & 5.33 & 827.13 \\
\hline France & 13.5 & & $1.44(0.84)$ & $0.88(0.06)$ & 1.08 & 11.61 & 10.51 & 0.00 & 0.00 & N.A. ${ }^{b}$ \\
\hline Greece & 8.0 & & $0.60(0.94)$ & $0.93(0.06)$ & 2.13 & 8.97 & 8.61 & 23.80 & 42.82 & 95.60 \\
\hline
\end{tabular}


Table 1: Comparison of GS as percentage of output and simulation results (contd)

\begin{tabular}{|c|c|c|c|c|c|c|c|c|c|c|}
\hline \multirow[b]{3}{*}{ Country } & \multirow{3}{*}{\begin{tabular}{|c|}
$\begin{array}{c}(1) \\
\text { Hamilton and } \\
\text { Clemens } \\
(1999)\end{array}$ \\
$\begin{array}{c}\text { GS as } \\
\text { percent of } \\
\text { GNP }\end{array}$
\end{tabular}} & \multirow{3}{*}{$\begin{array}{c}\text { (2) } \\
\begin{array}{c}\text { Arrow et al } \\
(2004)\end{array} \\
\text { GS as } \\
\text { percent of } \\
\text { GDP }\end{array}$} & \multicolumn{8}{|c|}{$\begin{array}{c}\text { (3) } \\
\text { This study }\end{array}$} \\
\hline & & & \multicolumn{4}{|c|}{ Estimated results of $A R(1)$ process } & \multicolumn{4}{|c|}{ Simulation results } \\
\hline & & & constant & $\beta$ & $\begin{array}{l}\text { St. dev. } \\
\text { of } \varepsilon\end{array}$ & $\begin{array}{c}\text { Steady } \\
\text { state GS } \\
\text { rate }\end{array}$ & $\begin{array}{c}\text { Initial } \\
\text { condition }\end{array}$ & $\begin{array}{c}\% \text { of } \\
\text { experiencing } \\
\text { negative GS in } \\
25 \text { years }\end{array}$ & $\begin{array}{c}\% \text { of } \\
\text { experiencing } \\
\text { negative GS in } \\
50 \text { years }\end{array}$ & $\begin{array}{c}\text { Average years } \\
\text { before having } \\
\text { negative GS }\end{array}$ \\
\hline \multicolumn{11}{|c|}{ High-Income Countries (contd) } \\
\hline Ireland & 17.4 & & $1.41(1.28)$ & $0.92(0.08)$ & 2.15 & 16.82 & 21.19 & 0.30 & 1.00 & $>1000$ \\
\hline Italy & 12.3 & & $2.51(1.05)$ & $0.79(0.08)$ & 0.87 & 11.71 & 10.69 & & 0.00 & N.A. \\
\hline Japan & 26.2 & & $1.10(0.97)$ & $0.92(0.05)$ & 1.50 & 14.46 & 15.11 & 0.00 & 0.19 & N.A. ${ }^{b}$ \\
\hline Netherlands & 15.6 & & $2.15(1.17)$ & $0.85(0.25)$ & 1.35 & 14.71 & 14.67 & 0.00 & 0.00 & N.A. ${ }^{b}$ \\
\hline New Zealand & 13.6 & & $4.13(2.31)$ & $0.60(0.25)$ & 2.13 & 10.20 & 15.13 & & 100.00 & N.A. ${ }^{a}$ \\
\hline Norway & 7.0 & & $1.29(1.04)$ & $0.90(0.07)$ & 1.88 & 13.03 & 14.65 & 0.80 & 2.08 & $>1000$ \\
\hline Portugal & 18.1 & & $1.26(1.16)$ & $0.83(0.12)$ & 2.48 & 7.55 & 1.36 & 58.20 & 71.33 & 43.84 \\
\hline Spain & 12.3 & & $1.39(1.00)$ & $0.88(0.08)$ & 1.16 & 11.69 & 11.96 & 0.00 & 0.00 & N.A. ${ }^{b}$ \\
\hline Sweden & 5.6 & & $3.32(1.53)$ & $0.79(0.09)$ & 1.67 & 15.99 & 18.59 & 0.00 & 0.00 & N.A. ${ }^{b}$ \\
\hline Switzerland & 19.9 & & $6.76(2.63)$ & $0.66(0.13)$ & 1.52 & 19.65 & 22.02 & 0.00 & 0.00 & N.A. ${ }^{b}$ \\
\hline Turkey & 15.4 & & $2.34(1.50)$ & $0.84(0.10)$ & 2.16 & 14.99 & 9.23 & 0.10 & 0.44 & $>1000$ \\
\hline United Kingdom & 6.6 & 7.38 & $1.62(0.70)$ & $0.78(0.08)$ & 1.29 & 7.38 & 7.12 & 0.30 & 0.63 & $>1000$ \\
\hline United States & 9.6 & 8.94 & $1.03(0.92)$ & $0.85(0.10)$ & 1.64 & 7.06 & 3.31 & 19.50 & 28.82 & 180.39 \\
\hline \multicolumn{11}{|l|}{ Other Countries } \\
\hline Bulgaria & & & $0.50(1.17)$ & $0.88(0.07)$ & 3.90 & 4.15 & 6.02 & 82.00 & 96.33 & 12.86 \\
\hline Hungary & & & $3.12(2.14)$ & $0.74(0.16)$ & 2.55 & 11.80 & 7.52 & 2.30 & 3.68 & $>1000$ \\
\hline
\end{tabular}

Note : (1) The first column recaps the result of Hamilton and Clemens (1999). Values presented are their sigle-year-estimates of GS as Percent of GNP in 1993 with exceptions of ${\left({ }^{*}\right)} 1992$ value, and $\left(^{* *}\right) 1991$ value. (2) The second column is for Arrow et al. (2004), who calculated the GS as percent of GDP and averaged them over the period from 1970 to 2001. (3) Our results: numbers in parentheses are the standard errors in our AR(1) estimations of GS rate process. Estimated steady state values of the GS rates are also provided. We simulate from the initial conditions which are the latest available values of GS rates in our dataset (2005 value with the exception for Fiji, 2000; Tonga, 2004; Trinidad and Tobago, 2004; Israel, 1998, Saudi Arabia, 2002; Burkina Faso, 2003; Cameroon, 1998; and Switzerland, 2003). Calculated two measures of future sustainability are (i) the percentage experiencing negative GS rate over 50 years, and (ii) the average number of years before the first negative GS rate appears in the stochastic process. With respect to (ii), if the probability is one, we report it as N.A. ; if it is zero (no breaking-the-future-sustainability-condition case), we report it as N.A ${ }^{\text {b }}$ 
Table A1: Variance of each capital component from VAR(1) estimations

\begin{tabular}{|c|c|c|c|c|c|c|}
\hline Country & $V_{K M}$ & $\mathrm{~V}_{\mathrm{KH}}$ & $V_{\text {ENERGY }}$ & $V_{\text {MINE }}$ & $V_{\text {FOREST }}$ & $\mathrm{V}_{\mathrm{CO} 2}$ \\
\hline \multicolumn{7}{|c|}{ Latin America and the Caribbean } \\
\hline Belize & 33.78 & 0.10 & N.A. & N.A. & N.A. & 0.00 \\
\hline Bolivia & 10.93 & 0.14 & 8.81 & 3.28 & N.A. & 0.00 \\
\hline Brazil & 2.72 & 0.10 & 0.14 & 0.05 & N.A. & 0.00 \\
\hline Chile & 4.27 & 0.05 & 0.07 & 3.27 & N.A. & 0.00 \\
\hline Costa Rica & 6.45 & 0.14 & N.A. & 0.00 & 0.03 & 0.00 \\
\hline Dominica & 18.56 & 0.01 & N.A. & N.A. & N.A. & 0.00 \\
\hline Dominican Republic & 13.94 & 0.04 & N.A. & 1.24 & N.A. & 0.01 \\
\hline Ecuador & 10.29 & 0.14 & 25.93 & 0.01 & N.A. & 0.02 \\
\hline El Salvador & 9.40 & 0.05 & N.A. & 0.00 & 0.02 & 0.00 \\
\hline Fiji & 15.88 & 0.10 & N.A. & 0.10 & N.A. & 0.00 \\
\hline Guatemala & 2.37 & 0.00 & 0.03 & 0.00 & 0.02 & 0.00 \\
\hline Honduras & 11.88 & 0.03 & N.A. & 0.40 & N.A. & 0.00 \\
\hline Jamaica & 12.80 & 0.28 & N.A. & 5.78 & N.A. & 0.02 \\
\hline Mexico & 3.41 & 0.10 & 7.27 & 0.05 & N.A. & 0.01 \\
\hline Nicaragua & 172.91 & 0.30 & N.A. & 0.06 & N.A. & 0.02 \\
\hline Paraguay & 14.82 & 0.07 & N.A. & N.A. & N.A. & 0.00 \\
\hline St. Vincent and the GreN & 54.91 & 0.23 & N.A. & N.A. & N.A. & 0.00 \\
\hline Tonga & 33.81 & 0.03 & N.A. & N.A. & 0.00 & 0.00 \\
\hline Trinidad and Tobago & 38.59 & 0.13 & 65.24 & N.A. & N.A. & 0.04 \\
\hline Uruguay & 16.67 & 0.04 & N.A. & N.A. & 0.01 & 0.00 \\
\hline Venezuela, RB & 17.55 & 0.17 & 70.17 & 0.03 & N.A. & 0.02 \\
\hline \multicolumn{7}{|l|}{ East Asia and the Pacific } \\
\hline ChiN.A. & 8.57 & 0.01 & 4.33 & 0.05 & 0.00 & 0.05 \\
\hline Hong Kong, ChiN.A. & 4.14 & 0.05 & N.A. & 0.00 & N.A. & 0.00 \\
\hline Korea, Rep. & 4.62 & 0.29 & 0.04 & 0.00 & N.A. & 0.00 \\
\hline Malaysia & 8.32 & 0.09 & 6.83 & 0.15 & 0.08 & 0.01 \\
\hline Philippines & 8.98 & 0.04 & 0.02 & 0.12 & 0.03 & 0.00 \\
\hline Thailand & 4.55 & 0.04 & 0.14 & 0.04 & 0.00 & 0.00 \\
\hline \multicolumn{7}{|l|}{ Middle/East North Africa } \\
\hline Algeria & 21.84 & 0.04 & 27.48 & 0.00 & 0.00 & 0.05 \\
\hline Israel & 9.27 & 0.23 & 0.41 & 0.00 & 0.00 & 0.00 \\
\hline Jordan & 46.28 & 0.34 & 0.00 & 0.06 & 0.01 & 0.01 \\
\hline Morocco & 4.36 & 0.10 & 0.00 & 2.70 & 0.00 & 0.00 \\
\hline Saudi Arabia & 22.30 & 0.22 & 32.72 & N.A. & N.A. & 0.01 \\
\hline Syrian Arab Republic & 18.85 & 0.18 & 21.53 & 0.01 & N.A. & 0.03 \\
\hline Tunisia & 2.12 & 0.06 & 2.48 & 0.02 & 0.00 & 0.00 \\
\hline \multicolumn{7}{|l|}{ South Asia } \\
\hline Bangladesh & 9.69 & 0.01 & 0.15 & N.A. & 0.06 & 0.00 \\
\hline India & 2.26 & 0.03 & 0.39 & 0.01 & 0.03 & 0.01 \\
\hline Nepal & 4.26 & 0.12 & 0.00 & 0.21 & 0.22 & 0.00 \\
\hline Pakistan & 6.60 & 0.02 & 0.38 & 0.00 & 0.01 & 0.00 \\
\hline Sri Lanka & 8.34 & 0.05 & N.A. & N.A. & 0.04 & 0.00 \\
\hline \multicolumn{7}{|l|}{ Sub-Saharan Africa } \\
\hline Benin & 12.29 & 0.02 & 0.89 & N.A. & 0.13 & 0.00 \\
\hline BotswaN.A. & 28.20 & 0.04 & 0.09 & 2.53 & N.A. & 0.00 \\
\hline BurkiN.A. Faso & 8.75 & 0.12 & N.A. & N.A. & 0.09 & 0.00 \\
\hline Cameroon & 23.10 & 0.03 & 15.09 & 0.01 & N.A. & 0.01 \\
\hline Congo, Dem. Rep. & 42.14 & 0.11 & 0.64 & 2.46 & N.A. & 0.00 \\
\hline Congo, Rep. & 131.84 & 1.04 & 152.58 & 0.21 & N.A. & 0.01 \\
\hline Cote d'Ivoire & 33.03 & 0.49 & 0.41 & N.A. & N.A. & 0.01 \\
\hline
\end{tabular}


Table A1: Variance of each capital component from VAR(1) estimations (contd)

\begin{tabular}{|c|c|c|c|c|c|c|}
\hline $\begin{array}{l}\text { Country } \\
\end{array}$ & $\mathrm{V}_{\mathrm{KM}}$ & $\mathrm{V}_{\mathrm{KH}}$ & $\mathrm{V}_{\text {ENERGY }}$ & $\mathrm{V}_{\text {MINE }}$ & $V_{\text {FOREST }}$ & $\mathrm{V}_{\mathrm{CO} 2}$ \\
\hline \multicolumn{7}{|c|}{ Sub-Saharan Africa (contd) } \\
\hline Ethiopia & 8.25 & 0.03 & N.A. & 0.00 & 1.10 & 0.00 \\
\hline GhaN.A. & 12.66 & 0.16 & 0.01 & 0.26 & 0.21 & 0.00 \\
\hline Kenya & 10.58 & 0.10 & N.A. & 0.00 & 0.10 & 0.00 \\
\hline Lesotho & 44.13 & 0.21 & N.A. & N.A. & 0.17 & N.A. \\
\hline Madagascar & 14.18 & 0.08 & N.A. & 0.00 & N.A. & 0.00 \\
\hline Mauritania & 208.73 & 0.17 & N.A. & 24.18 & 0.00 & 0.04 \\
\hline Mauritius & 2.83 & 0.08 & N.A. & N.A. & 0.00 & 0.00 \\
\hline Rwanda & 17.40 & 0.04 & 0.00 & 0.07 & 0.40 & 0.00 \\
\hline Senegal & 18.47 & 0.04 & 0.00 & 0.17 & N.A. & 0.01 \\
\hline Sierra Leone & 32.99 & 0.19 & N.A. & 0.33 & 0.22 & 0.01 \\
\hline South Africa & 1.68 & 0.25 & 0.27 & 0.14 & 0.00 & 0.03 \\
\hline Swaziland & 23.75 & 0.21 & 0.03 & 0.99 & 1.92 & 0.01 \\
\hline Togo & 14.72 & 0.10 & N.A. & 0.19 & 0.30 & 0.01 \\
\hline Uganda & 9.99 & 0.35 & N.A. & 0.01 & 3.31 & 0.00 \\
\hline Zambia & 39.58 & 0.13 & 0.02 & 16.64 & N.A. & 0.01 \\
\hline Zimbabwe & 24.09 & 0.17 & 0.44 & 0.40 & N.A. & 0.09 \\
\hline \multicolumn{7}{|c|}{ High-Income Countries } \\
\hline Australia & 1.54 & 0.02 & 0.29 & 0.12 & N.A. & 0.00 \\
\hline Austria & 1.28 & 0.03 & 0.01 & 0.00 & N.A. & 0.00 \\
\hline Belgium & 7.40 & 0.24 & 0.00 & 0.01 & 0.03 & 0.00 \\
\hline CaN.A.da & 1.68 & 0.08 & 1.31 & 0.06 & N.A. & 0.00 \\
\hline Denmark & 0.99 & 0.06 & 0.07 & 0.00 & 0.00 & 0.00 \\
\hline Finland & 5.82 & 0.08 & N.A. & 0.00 & N.A. & 0.00 \\
\hline France & 1.29 & 0.02 & 0.00 & 0.00 & N.A. & 0.00 \\
\hline Greece & 4.18 & 0.03 & 0.01 & 0.00 & 0.05 & 0.00 \\
\hline Ireland & 4.66 & 0.04 & 0.02 & 0.03 & N.A. & 0.00 \\
\hline Italy & 0.47 & 0.08 & 0.00 & 0.00 & N.A. & 0.00 \\
\hline Japan & 1.91 & 0.03 & 0.00 & 0.00 & N.A. & 0.00 \\
\hline Netherlands & 1.42 & 0.03 & 0.38 & 0.00 & N.A. & 0.00 \\
\hline New Zealand & 5.26 & 0.31 & 0.07 & 0.00 & 0.00 & 0.00 \\
\hline Norway & 7.45 & 0.08 & 6.12 & 0.00 & N.A. & 0.00 \\
\hline Portugal & 5.99 & 0.03 & 0.00 & 0.00 & N.A. & 0.00 \\
\hline Spain & 0.57 & 0.03 & 0.00 & 0.00 & N.A. & 0.00 \\
\hline Sweden & 3.33 & 0.06 & 0.00 & 0.01 & 0.00 & 0.00 \\
\hline Switzerland & 1.96 & 0.02 & 0.00 & N.A. & 0.00 & 0.00 \\
\hline Turkey & 4.53 & 0.10 & 0.02 & 0.00 & N.A. & 0.01 \\
\hline United Kingdom & 1.09 & 0.03 & 0.34 & 0.00 & N.A. & 0.00 \\
\hline United States & 1.42 & 0.20 & 0.36 & 0.00 & N.A. & 0.00 \\
\hline \multicolumn{7}{|l|}{ Other Countries } \\
\hline Bulgaria & 16.91 & 0.07 & 0.07 & 0.34 & N.A. & 0.13 \\
\hline Hungary & 7.05 & 0.22 & 0.14 & 0.00 & N.A. & 0.01 \\
\hline
\end{tabular}

Note: $\mathrm{V}_{\mathrm{KM}}, \mathrm{V}_{\mathrm{KH}}, \mathrm{V}_{\mathrm{ENERGY}}, \mathrm{V}_{\mathrm{MINE}}, \mathrm{V}_{\mathrm{FOREST}}$ and $\mathrm{V}_{\mathrm{CO} 2}$ are repsectively the variance of man-made capital (net national saving), human capital (education expenditure), energy depletion, mineral depletion, forest depletion and $\mathrm{CO} 2$ emission. The sample size for conducting $\operatorname{VAR}(1)$ estimation is the same as that of $\operatorname{AR}(1)$ process. Due to the lack of data, the variances of some components of GS in some countries can not be estimated. We report them as N.A. in the table. 